\title{
Review of Recent Lifecycle Assessments of Energy and Greenhouse Gas Emissions for Electric Vehicles
}

\author{
R. Nealer ${ }^{1}$ T. P. Hendrickson ${ }^{2}$
}

Published online: 11 July 2015

(C) Springer International Publishing AG 2015

\begin{abstract}
This paper synthesizes the most recent studies on the lifecycle of electric vehicles (EVs), summarizes the critical assumptions and inputs of the lifecycle assessments (LCAs), and discusses policy context affecting these assessments. The use phase represents the majority of environmental impacts for EVs, particularly in areas with more fossil fuel use in the electricity grid mix. Assumptions made in LCAs about electricity generation, vehicle lifetime, vehicle weight, and driving behavior greatly impact the resulting lifecycle energy consumption and greenhouse gas (GHG) emissions of EVs. However, vehicle and battery considerations outside of vehicle use affect the lifecycle environmental performance of EVs as well. The battery manufacturing and end-of-life (EOL) technologies and processes are still being developed and researched, and manufacturing batteries has some uncertainties but is a large contributor to the manufacturing emissions of EVs. Recycling and second-life applications present an opportunity for increasing the value and lowering environmental impacts of EV batteries. Policies today help to get EVs on the road by reducing costs to own EVs, but more research and policies can be developed to improve the state of battery technology. Future policies focusing on battery manufacturing and EOL and a cleaner electricity grid can have the potential to reduce the environmental burden of EVs by encouraging recycling
\end{abstract}

This article is part of the Topical Collection on Transportation

R. Nealer

rnealer@gmail.com

T. P. Hendrickson

tphendrickson@berkeley.edu

1 Union of Concerned Scientists, Washington, DC 20006, USA

2 Civil and Environmental Engineering, University of California, Berkeley, Berkeley, CA 94720, USA batteries, producing batteries more efficiently, and reducing emissions from the electricity grid.

Keywords Electric vehicle review - Lifecycle assessment . Policy implications · Energy and GHG emissions

\section{Introduction}

Lifecycle assessment (LCA) has quickly become the standard in comparing the environmental costs and benefits of electric vehicles (EVs) and gasoline vehicles. LCA provides a more complete framework to evaluate the tradeoffs for vehicles. The major differences between EVs and gasoline vehicles are in the use of the vehicle and the additional battery manufacturing and disposal. EV is a broad term which includes hybrid electric vehicles (HEVs), plug-in electric vehicles (PEVs), and battery electric vehicles (BEVs). Hybrid electric vehicles do not plug into electricity and use a gasoline tank and engine with a slightly larger battery which stores energy from regenerative braking. PEVs do plug into electricity but also have a smaller gasoline tank and engine which only engages when the battery is depleted. BEVs only plug into electricity, run completely on the battery, and have no gasoline tank or engine.

This next section discusses the recent literature, but starts with the Hawkins et al. [1•] review where they reviewed 51 lifecycle studies of hybrid and electric vehicles. They found most studies report $\mathrm{CO}_{2}$ emissions, but the scope and methods of the individual LCAs made them difficult to compare. Specifically, how the studies define their LCA boundaries to include and exclude various greenhouse gas (GHG) emissions sources and the lifetime over which they calculate the vehicle's GHG emissions make study-to-study comparisons difficult. Thus, Hawkins et al. [1•] compared the vehicle and 
battery production, electricity generation, fuel production, energy efficiency, and fuel combustion for GHG emissions separately. After adjusting for a common 200,000-km (125,000 mi) lifetime, the GHG emissions scaled better with vehicle weight than with vehicle lifetime mileage. With respect to battery manufacturing, more recent studies have resulted in higher GHG emissions, which Hawkins et al. [1•] attributes to more complete inventories and better process understanding of producing batteries. The expected lifetime of the batteries has also been increasing over the years, resulting in most studies using a battery lifetime similar to the vehicle lifetime: only one battery required per EV. A concluding result of the review is the need for studies to examine the real-world driving conditions and emissions related to driving EVs.

The recent peer-reviewed literature on EVs ranges in scope and numerical results, but most come to the same conclusion that EVs have the potential to reduce GHG emissions. Since the Hawkins et al. [1 $[$ review, a few complete cradle-to-grave lifecycle assessments have been published, including one by Hawkins et al. [2•], though other studies with focus on the EV battery have been published and are discussed later. In the LCA of EVs by Hawkins et al. [2•], they use process level energy and GHG emissions data to show EVs result in fewer GHG emissions than gasoline vehicles, but other impacts, like eco-toxicity, may be higher than gasoline vehicles. Mostly recently, Dunn et al. [3•] modeled the LCA of EVs with various battery chemistries and electricity grids (described more in the battery section) and they find the BEVs and PEVs result in fewer GHG emissions than the average gasoline car. The Department of Energy produced a study [4] comparing the complete cradle-to-grave lifecycle GHG emissions of EVs and results in similar conclusions to Hawkins et al. [2•] that HEVs, PEVs, and shorter-range BEVs reduce GHG emissions compared to the average gasoline vehicle, but longer-range $\mathrm{BEVs}$ are comparable to the average gasoline vehicle. A study by Michalek et al. [5] monetized the lifecycle GHG emissions and criteria pollutants of EVs and oil displacement benefits. They found that EVs with larger battery packs are more expensive, heavier, and more emissions-intensive to produce, and provide emissions benefits less than HEVs and PEVs with smaller battery packs. Though all EVs reduce emissions compared to the average gasoline vehicle in their base case and optimistic case. In an LCA by Shen [6], they find $18.5 \%$ of the energy and $17 \%$ of the GHG emissions come from the production of the EV and the remaining $81.5 \%$ and $83 \%$ come from the use, respectively. In the literature that explores the total cradle-to-grave energy and GHG emissions of EVs, each study estimates the emissions from the use of the vehicle outweigh the emissions from manufacturing the vehicle.

Various other reports and articles have been published that look at parts of the lifecycle of EVs, some on the specifics of battery manufacturing and recycling as noted later in the paper
$[3 \cdot, 7 \cdot, 8]$, but also some on the use of the vehicles today over various electricity grid regions $[1 \cdot, 9-12]$. The electricity grid and when EVs are charged remain a major contributor to the GHG emissions of EVs. Overall, the GHG emissions of BEVs powered by coal reduce GHG emissions compared to gasoline vehicles but may be higher than high-efficiency gasoline vehicles and HEVs. However, PEVs or BEVs powered on cleaner sources of electricity can produce fewer GHG emissions than HEVs and gasoline vehicles, even the more efficient models [1•].

This paper synthesizes the most recent studies on the lifecycle of EVs, summarizes the most sensitive assumptions and inputs of the LCAs, and adds policy context surrounding EVs today. The use phase section condenses many of the studies mentioned above into a few key assumptions that are important to the resulting GHG emissions from EVs. Then, a more detailed summary of the research on the largest difference between EVs and other vehicles, the lithium-ion battery (LIB), is presented. Finally, a summary of the current policies and where policies could benefit from more research is discussed. Most of the current LCA studies on EVs do not connect the technical research and policies as this paper does. Policies have the opportunity to shape how quickly and how many EVs are adopted, as well as provide valuable data to update the lifecycle energy and GHG emissions benefits of EVs in use today and in the future.

\section{Use Phase of Electric Vehicles}

The use phase of an EV has little to no tailpipe emissions, but does produce emissions when generating the electricity required to drive. The use phase of EVs is the majority of the GHG emissions over the total lifetime of the car, and in current literature, results suggest the use phase accounts for approximately 60 to $90 \%$ of the total lifecycle GHG emissions [1•]. This section discusses some of the most important inputs for the use phase of the lifecycle GHG emissions of EVs: electricity generation, vehicle lifetime, vehicle weight, and driving behavior.

\section{Electricity Generation Assumptions}

Use phase GHG emissions result from the electricity generated to power the vehicle and the supply chain emissions required to produce the electricity. The supply chain emissions of electricity generation include extracting the fuel source, processing it, and transporting it for consumption.

There are two ways to estimate the emissions from electricity generation: average or marginal GHG emissions from the electricity grid mix for a region. There is an ongoing debate about whether it is more appropriate to use marginal or average electricity to estimate GHG emissions from EVs; depending on the electricity mix, this could significantly affect the results. The Union of Concerned Scientists [9] published a report on the regional electricity grid variability of emissions from an average 
EV, and Climate Central [13] published a report on EV GHG emissions by state. Both reports use average regional electricity grid mixes and find that EVs produce fewer GHG emissions than the average gasoline vehicle, but how much better depends on where the vehicle is charged. Others have utilized marginal emissions to look at the dispatched electricity at the time of charging to estimate GHG emissions of EV use. Yuksel [10] found that BEV emissions can vary up to $22 \%$ due to spatial and temporal variation. Graff Zivin [11] analyzed the impact of marginal electricity as a method to evaluate GHG emissions of EVs showing that often when charging is cheapest GHG, the emissions from the electricity grid are highest.

Some researchers $[10,11,14]$ assert that the use of marginal emissions is the best way to measure emissions because it more accurately describes the current state of the emissions from plugging in to the electricity grid when a consumer uses an EV. However, the data are often limited because quantifying which power plant is dispatching electricity at a specific time and day is data intensive, is difficult to estimate without complex modeling, and relies on many assumptions about when and where consumers are plugging in their vehicles. Therefore, the use of average emissions across various electricity regions has become more accessible and has served as a reasonable estimate for GHG emissions for EVs [4, 9, 13, 15]. Though Weber [16 ${ }^{\bullet}$ shows that the regional averages can be significantly different than the US average and must be taken into consideration. A major determination for which method to use, marginal or average, depends on the time period for which to evaluate EVs. When looking at how the electricity grid can improve over time and comparing it to today's grid, average GHG emissions of the grid may be the most accessible for long-term comparisons given the assumptions that must be made about the future of the electricity grid.

\section{Vehicle Lifetime Assumptions}

Deciding the lifetime of the vehicle, in mileage or years, could artificially increase or decrease the resulting emissions per mile for an EV. The common way to measure LCAs of vehicles for fair comparison is emissions or energy over the vehicle lifetime. The lifetime is usually measured in distance or sometimes years. This metric is important because it is the amount of miles or time by which you normalize the emissions. For example, a common lifetime is $200,000 \mathrm{~km}$ or 160 , 000 miles. If you were to assume a longer lifetime, the emissions per kilometer or mile would decrease, even if the emissions themselves did not change, or even increased slightly due to additional use of the vehicle. Conversely, if you were to assume a shorter lifetime, the emissions per kilometer would be higher. This is often a point of confusion in the general public and media and sometimes used to skew the results in either direction making EVs look worse or better with an erroneous vehicle lifetime.

\section{Vehicle Weight Assumptions}

The way most LCAs measure the GHG emissions from producing EVs today is by modeling the emissions from producing the materials and summing them for the entire vehicle. In general, more material requires more energy and produces more GHG emissions, but also, the type of materials used is important. EV manufacturers may try to reduce weight to decrease the costs of the battery needed while holding the battery performance constant in terms of vehicle range. Many of the vehicle LCAs rely on a publicly available model developed by Argonne National Lab, the Greenhouse Regulated Energy and Emissions in Transportation (GREET) which uses tear-down studies and publicly available data to estimate the supply chain energy and GHG emissions by material based on weight [17]. This limits the ability to model the lifecycle energy and emissions associated with specific vehicles, unless more information is known about the composition of the vehicles. The type of materials used and the amount of materials used based on the weight assumptions can produce a range of lifecycle energy and GHG emissions.

The range of vehicle weight for EVs today is large mostly due to varying battery sizes available, but also because of the materials used in the vehicles. For example, the BMW i3 curb weight is $2700 \mathrm{lb}$ [18] whereas the largest available Tesla Model S curb weight is $60 \%$ higher at $4650 \mathrm{lb}$ [19]. A large part of this difference is related to the lithium-ion battery (LIB) where the BMW i3 $22 \mathrm{kWh}$ battery weighs $500 \mathrm{lb}$ and the Tesla Model S $85 \mathrm{kWh}$ battery weighs $1200 \mathrm{lb}$. However, there are other differences, like the use of carbon fiber reinforced plastics in the BMW i3 and a mostly aluminum body in the Tesla Model S that reduce the overall weight of the vehicle, compared to conventional steel vehicle bodies. The specifics of these vehicles are difficult to model given their unique processes and limited data publicly available.

\section{Driving Behavior Assumptions}

How much highway and urban driving and how aggressive a driver may drive an EV also impact the use energy and GHG emissions of the EV. The Environmental Protection Agency (EPA) regulates the tailpipe emissions from vehicles and determines emissions using driving cycle tests. Aggressive driving, such as faster acceleration and braking, results in more energy consumption and GHG emissions than moderate acceleration and braking. Similarly, more urban driving of a gasoline car results in more energy consumption and GHG emissions than highway driving. EPA combines how much average drivers spend driving in urban areas versus highway to get one single miles per gallon or miles per gallon equivalent estimate. If in reality, people drive differently from the driving cycle test then their energy consumption and GHG emissions could be different than what the EPA estimates. PEVs rely on both gasoline and batteries to drive, and how much they rely on the gasoline is 
related to how large the battery is and the type of driving. By varying driving behavior alone, the results of energy consumption and GHG emissions can reduce PHEV GHG emissions by $60 \%$ for urban driving compared to gasoline cars, but can also reduce electric range of PEVs by up to $45 \%$ for aggressive driving [20].

\section{Vehicle and Battery Manufacturing and End of Life for Electric Vehicles}

Assessments must account for vehicle and battery considerations outside of use when utilizing lifecycle methodologies. Production and post-use processes can greatly affect the environmental performance of EVs. The rapidly changing nature of EV technology ensures that researchers will continually encounter new challenges, including manufacturing processes, recycling technologies, and reuse applications.

The vehicle manufacturing of EVs consists of all vehicle elements outside of battery production, which has complexities that warrant its separation from the rest of the vehicle in environmental assessments. LCAs in vehicle manufacturing of EVs range in methodologies from top-down approaches that combine general specifications with existing LCA models [12, 21] to bottom-up methods that determine environmental outputs from detailed lifecycle inventories $[1 \bullet, 3 \bullet, 22 \cdot]$. Assessments in vehicle manufacturing have wide-ranging environmental criteria, but most studies focus on results for energy demands and GHG emissions. Figure 1 displays results for selected studies in vehicle manufacturing of EVs. EV LCA results commonly use a measure of distance driven as a functional unit, expressed in Fig. 1, which can skew final manufacturing results as assumptions vary for driving distances $[1 \bullet, 8]$.

Lifecycle research has consistently determined that batteries represent a significant portion of environmental impacts in EV manufacturing, ranging from 10 to $75 \%$ of total manufacturing energy demand $[3 \bullet, 22 \cdot]$ and $10-70 \%$ of manufacturing GHG emissions $[1 \bullet, 3 \bullet, 12,21,22 \cdot]$. EV batteries are a highly dynamic research area as designs continue to evolve. Current research trends focus on LIBs, most notably $\mathrm{LiMn}_{2} \mathrm{O}_{4}$ (LMO), $\mathrm{LiFePO}_{4}$ (LFP), and $\mathrm{LiNi}_{0.4} \mathrm{Mn}_{0.4} \mathrm{Co}_{0.2} \mathrm{O}_{2}$ (NMC) chemistries [3•, 7•, 8, 22•, 23-27, 28•]. Like vehicle manufacturing, these LCAs have a wide range of environmental criteria in results, but many consistently report GHG emissions and total energy demand. Compiled results for these studies can be found in Fig. 1. Facility size and state of technology can significantly affect battery LCA results, as developed manufacturing technologies that can leverage economies of scales will improve efficiency while reducing impacts [3•]. For EV assessments seeking to utilize existing literature values, one must carefully select studies based on methods, materials, and processes assessed, as Fig. 1 shows large variations in results for both vehicle and battery manufacturing
LCAs. The difference in results can be attributed to the methodologies employed in vehicle manufacturing LCA (i.e., topdown and bottom-up), battery designs, and manufacturing processes, particularly battery assembly $[3 \bullet, 7 \bullet]$.

Research has increased significantly in the past several years on EV battery end-of-life options. This research area has focused mainly in battery recycling technologies and second-life applications. Assessments of EV battery recycling technologies have included both commercially available and developing systems including pyrometallurgy, hydrometallurgy, direct physical, and intermediate physical recycling processes [3•, 7•, 8, 28•]. Pyrometallurgy is currently the only commercially available technology, but the other three technologies are capable of recovering more materials, most notably lithium. The challenge for LIB recycling technologies is remaining economical and flexible as LIB chemistries shift to lower-cost active materials (i.e., anodes, cathodes) [28•]. LCA results for these recycling technologies are summarized in Fig. 1. As is the case with manufacturing, Fig. 1 reveals that EV battery recycling LCAs can vary substantially for the different recycling technologies and battery chemistries. This again can be attributed to the methodologies and scopes of these studies, which dictate the final results.

Before disposal, EV LIBs have the potential to utilize their remaining capacity for energy storage, as batteries typically are not favorable for vehicle use at less than $70 \%$ capacity [29•]. EV LIB energy storage creates an opportunity for lifecycle environmental savings as LIB storage can facilitate grid integration of renewable energy sources. Studies have assessed this potential benefit from mainly economic perspectives [30-32], but environmental impact studies have emerged in recent research [29•, $31,33,34 \cdot$. The studies, while ranging in scopes and methodologies, generally found that as EV use scaled up, increased storage would create significant saving opportunities from post-use LIBs, particularly for renewable energy sources that can displace fossil fuel use [29•, 30, 31]. The difficulty in analyzing EV battery second-life applications is the lack of data available for predicting LIB degradation beyond vehicle use [29•]. Regional variations for electricity mixes displaced by stored renewable energy can greatly affect the impact abatement potential of EV LIB storage [34•]. This area of research will progress as second-life applications have major potential for increasing EV lifecycle value and abating environmental impacts.

\section{Policies for Electric Vehicles}

For emerging technologies like EVs, policy can serve as an important driver in reducing costs and making the technology available for broad adoption to reduce environmental impacts from the transportation sector. It is important to understand the costs and benefits of the policies in order to develop the most efficient use of our common resources and make sure environmental impacts are reduced and not just shifted. Most of the 

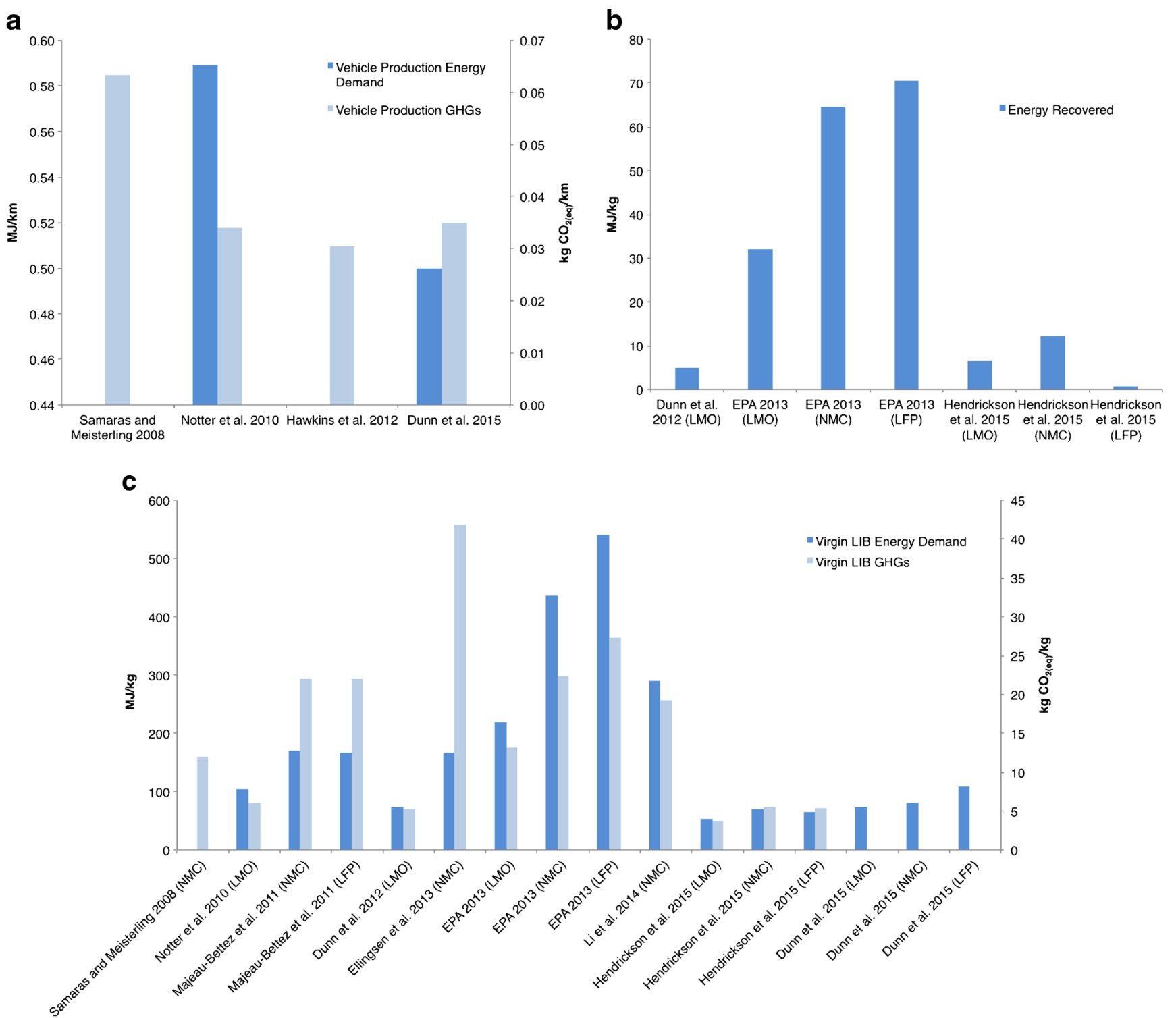

Fig. 1 a LCA literature results for vehicle production outside of battery requirements (per $\mathrm{km}$ traveled in vehicle lifetime). b LCA literature for lithium-ion battery (LIB) recycling (per kg of battery). Energy recovered denotes energy saved in avoiding the production of virgin materials.
Dunn et al. assessed hydrometallurgy recycling. EPA 2013 presented results as an average of hydrometallurgy, pyrometallurgy, and direct physical processes. Hendrickson et al. assessed pyrometallurgy recycling. c LCA LIB production literature from virgin materials (per kg of battery) policies for EVs today are implemented at the state or regional level, with the exception of the federal tax rebate. As the market for EVs continues to grow, these policies may change and could have significant impacts on the quantity and rate at which EVs are adopted and how quickly GHG emissions can be mitigated. This section reviews some policies available today, and comments on areas for which policies could be focused to reduce the energy and GHG emission burdens of EVs. In addition, some of these policies could facilitate more accurate modeling of future EV LCAs if data are collected and made publicly accessible. This data sharing could in turn expose areas where EV benefits could be maximized and energy requirements and GHG emissions minimized.
Most of the incentives and policies today are focused around making EVs more accessible to consumers. These policies take the form of monetary incentives to reduce the upfront cost of EVs and other incentives, like access to high-occupancy vehicle (HOV) lanes [35]. There is one federal level tax rebate, but states have developed the majority of the policies to encourage EV adoption. The largest incentives are often correlated with higher sales of EVs, and these effects can be seen in California, other west coast states, and Georgia [35]. The state policies allow flexibility to tailor policies to states where electricity emissions are lower and the GHG benefits of EVs are higher. Coupled with renewable energy standards (RES) by states, the benefits of EVs can be furthered. 
Research and development for battery manufacturing and recycling is also a critical piece to the success and energy and GHG emission benefits of EVs. The programs that are funded today to assist in this developmental research happen at various levels. The advanced research projects agency-energy (ARPA-E) funded by the federal government focuses on narrow projects that intend to be scaled up to industrial levels [36]. The national labs like Argonne National Lab and the Joint Center for Energy Storage Research (JCESR) also specialize in developing processes to advance battery technology at the laboratory-scale [37]. Other programs like the Department of Energy's Loan Guarantee program offered loans to vehicle manufacturers to make EVs more accessible with the technology available today [38]. These types of private-public partnerships are necessary to bridge the gap between optimizing battery production and recycling at the lab scale to the industrial scale where more vehicles can be produced and offered to meet the needs of a range of consumers. Increasing the scales of economy through this type of work will likely decrease the environmental impact per battery over time as has been shown in other new technologies like renewable electricity generation [39].

At this point in time, battery costs are a major impediment to offering EVs to large audiences and drives research in battery technology which will likely also reduce the environmental impact of the batteries as materials are reduced and processes are streamlined. Although the current price of batteries, around $\$ 300$ per kilowatt-hour, are lower than where experts expected it to be at this point in time, in order for EVs to be widely accessible, the prices of batteries are expected to be around $\$ 100-150$ per kilowatt-hour [40]. Continued research, optimization of battery chemistry and size, and scaling up the manufacturing process get closer to the point where EVs might be adopted more broadly and optimizing the chemistry and size of batteries. As researchers develop more efficient batteries, greater flexibility for longer-range batteries at a lower weight is enabled. Similarly, current battery ranges of 265 miles or more can be achieved at lower costs with these developments.

On the infrastructure side there are efforts to build up the needs similar to gas stations for EVs by way of public charging stations and most importantly workplace charging. It has been shown [41] that most people who currently drive EVs charge up at home or at work, where they know charging will be available. The Department of Energy has a current Workplace Charging Challenge [42] to encourage this growth. Similarly, the west coast states have even developed the West Coast Electric Highway for easier travel and eco-tourism [43].

\section{Conclusions}

Many LCAs have been published, and all suggest EVs have the capability to reduce GHG emissions compared to gasoline vehicles, and LCA has proven a valuable way to ensure GHG emissions are reduced instead of shifting them. EVs utilize dynamic technologies and have the potential for widespread, global implementation in the coming decades while also reducing the use of gasoline and GHG emissions from the transportation sector. Studying the processes to produce and operate EVs is frequently updated with new data which is critical in determining opportunities for maximizing the environmental benefit of EVs, and policies can help facilitate these developments.

The LCA literature shows the main contributor to GHG emissions of EVs is the use, and the most important factors in estimating those emissions are the electricity mix, vehicle lifetime, and driver behavior. Battery manufacturing and battery end of life are still being developed and researched, and manufacturing batteries is a large contributor to the manufacturing emissions of EVs. Recycling and second-life applications present an opportunity for increasing the value and lowering environmental impacts of EV batteries. LCAs help to reveal the largest sources of energy and GHG emissions which can help prioritize policies to gain the greatest overall benefits from EVs' potential to reduce GHG emissions, but also where more data are needed to better inform policy and EV deployment decisions. Policies today help to get EVs on the road by reducing costs, but more research and policies can be developed to improve the state of battery technology, make EVs more efficient, recycle batteries, produce batteries more efficiently, and reduce emissions from the electricity grid. LCA provides a unique framework to estimate and track the total GHG emissions of manufacturing, using, and disposing of EVs as they develop and ensure the GHG emissions decrease with new technology advances.

\section{Compliance with Ethics Guidelines}

Conflict of Interest The authors declare that they have no competing interests.

Human and Animal Rights and Informed Consent This article does not contain any studies with human or animal subjects performed by any of the authors.

\section{References}

Papers of particular interest, published recently, have been highlighted as:

- Of importance

1. Hawkins T, Gausen O, Stromman A. Environmental impacts of hybrid and electric vehicles - a review. Int J Life Cycle Assess. 2012;17:997-1014.

2. Hawkins TR, Singh B, Majeau-Bettez G, Strømman AH. Comparative environmental life cycle assessment of conventional and electric vehicles. J Ind Ecol. 2013;17(1):53-64. 
3. Dunn JB, Gaines L, Kelly JC, James C, Gallagher KG. The significance of Li-ion batteries in electric vehicle lifecycle energy and emissions and recycling's role in its reduction. Energy Environ Sci. 2014;8(1):158-68.

4. Department of Energy (DOE). Cradle to grave lifecycle analysis of vehicle and fuel pathways. DOE Hydrogen and Fuel Cells Program Record, 2014. [cited 2014 3/21/2014]Available from: http://www.hydrogen.energy.gov/pdfs/14006_cradle_to_grave analysis.pdf.

5. Michalek J, Chester M, Jaramillo P, Samaras C, Shiau C, Lave L. Valuation of plug-in vehicle life-cycle air emissions and oil displacement benefits. Proc Natl Acad Sci. 2011.

6. Shen W, Zhang B, Zhang Y, Wang X, Lu Q, Wang C. Research on life cycle energy consumption and environmental emissions of light-duty battery electric vehicles. Mater Sci Forum. 2015;814: 447-57.

7. Dunn JB, Gaines L, Sullivan J, Wang MQ. Impact of recycling on cradle-to-gate energy consumption and greenhouse gas emissions of automotive lithium-ion batteries. Environ Sci Technol. 2012;46(22):12704-10.

8. U.S. EPA. Application of lifecycle assessment to nanoscale technology: lithium-ion batteries for electric vehicles 2013 [cited 2013 10/22/2013]; Available from: http://www2.epa. gov/sites/production/files/2014-01/documents/lithium_ batteries_lca.pdf.

9. Anair D, Mahmassani A. Union of concerned scientists. State of charge. 2012 [cited 2012 6/2012] Available from: http://www. ucsusa.org/sites/default/files/legacy/assets/documents/clean vehicles/electric-car-global-warming-emissions-report.pdf.

10. Yuksel T, Michalek J. Effects of regional temperature on electric vehicle efficiency, range, and emissions in the United States. Environ Sci Technol. 2015;49(6):3974-80.

11. Graff Zivin J, Kotchem MJ, Mansur ET. Spatial and temporal heterogeneity of marginal emissions: implications for electric cars and other electricity-shifting policies. J Econ Behav Organ. 2014;107: 248-68.

12. Samaras C, Meisterling K. Life cycle assessment of greenhouse gas emissions from plug-in hybrid vehicles: implications for policy. Environ Sci Technol. 2008;42(9):3170-6.

13. Climate Central. A roadmap to climate-friendly cars: 2013, 2013 [cited 2013 10/2013] Available from: http://assets.climatecentral. org/pdfs/ClimateFriendlyCarsReport_Final.pdf.

14. Traut E, Hendrickson C, Klampfl E, Liu Y, Michalek J. Optimal design and allocation of electrified vehicles and dedicated charging infrastructure for minimum life cycle greenhouse gas emissions and cost. Energy Policy. 2013;51:524-34.

15. Electric Power Research Institute (EPRI), Natural Resource Defense Council (NRDC). Environmental assessment of plug-in hybrid electric vehicles. 2007, [cited 2007 5/23/15] Available from: http://mydocs.epri.com/docs/CorporateDocuments/SectorPages/ Portfolio/PDM/PHEV-ExecSum-vol1.pdf.

16. Weber C, Jaramillo P, Marriott J, Samaras C. Life cycle assessment and grid electricity: what do we know and what can we know? Environ Sci Technol. 2010;22:1895-901.

17. Argonne National Lab (ANL). Greenhouse gases, regulated emissions, and energy use in transportation model, 2014. [cited 2014 10/ 3/2014]Available from: https://greet.es.anl.gov/.

18. BMW. Features and Specs, 2015. [cited 2015 5/23/2015] Available from: http://www.bmwusa.com/Standard/Content/Vehicles/2015/ i3/BMWi3/Features_and_Specs/BMWi3Specifications.aspx.

19. Tesla Motors. Model S, 2015. [cited 2015 5/23/2015] Available from: http://www.teslamotors.com/models/specs.

20. Karabasoglu O, Michalek J. Influence of driving patterns in life cycle cost and emissions of hybrid and plug-in electric vehicle powertrains. Energy Policy. 2013;60:445-61.
21. Cooney G, Hawkins TR, Marriott J. Life cycle assessment of diesel and electric public transportation buses. J Ind Ecol. 2013;17(5): 689-99.

22. Notter DA, Gauch M, Widmer R, Wager P, Stamp A, Zah R, et al. Contribution of Li-ion batteries to the environmental impact of electric vehicles. Environ Sci Technol. 2010;44(17): 6550-6.

23. Dewulf J, Van der Vorst G, Denturck K, Van Langenhove H, Ghyoot W, Tytgat J, et al. Recycling rechargeable lithium ion batteries: critical analysis of natural resource savings. Resour Conserv Recycl. 2010;54(4):229-34.

24. Zackrisson M, Avellán L, Orlenius J. Life cycle assessment of lithium-ion batteries for plug-in hybrid electric vehicles - critical issues. J Clean Prod. 2010;18(15):1519-29.

25. Majeau-Bettez G, Hawkins TR, Strømman AH. Life cycle environmental assessment of lithium-ion and nickel metal hydride batteries for plug-in hybrid and battery electric vehicles. Environ Sci Technol. 2011;45(10):4548-54.

26. Ellingsen LAW, Majeau-Bettez G, Singh B, Srivastava AK, Valøen LO, Strømman AH. Life cycle assessment of a lithium-on battery vehicle pack. J Ind Ecol. 2014;18(1):113-24.

27. Li B, Gao X, Li J, Yuan C. Life cycle environmental impact of highcapacity lithium ion battery with silicon nanowires anode for electric vehicles. Environ Sci Technol. 2014;48(5):3047-55.

28. Hendrickson TP, Kavvada O, Shah N, Sathre R, Scown CD. Lifecycle implications and supply chain logistics of electric vehicle battery recycling in California. Environ Res Lett. 2015;10(1): 014011 .

29. Sathre R, Scown CD, Kavvada O, Hendrickson TP. Energy and climate effects of second-life use of electric vehicle batteries in California through 2050. J Power Sources. 2015;288:82-91.

30. Neubauer J, Pesaran A. The ability of battery second use strategies to impact plug-in electric vehicle prices and serve utility energy storage applications. J Power Sources. 2011;196(23): 10351-8.

31. Ahmadi L, Yip A, Fowler M, Young SB, Fraser RA. Environmental feasibility of re-use of electric vehicle batteries. Sustain Energy Technol Assess. 2014;6:64-74.

32. Ambrose H, Gershenson D, Gershenson A, Kammen D. Driving rural energy access: a second-life application for electric-vehicle batteries. Environ Res Lett. 2014;9(9):094004.

33. Ahmadi L, Fowler M, Young SB, Fraser RA, Gaffney B, Walker SB. Energy efficiency of Li-ion battery packs re-used in stationary power applications. Sustain Energy Technol Assess. 2014;8:9-17.

34. Faria R, Marques P, Garcia R, Moura P, Freire F, Delgado J, et al. Primary and secondary use of electric mobility batteries from a life cycle perspective. J Power Sources. 2014;262:169-77.

35. International Council on Clean Transportation (ICCT). Evaluation of state-level U.S. Electric Vehicle Incentives. 2014. [cited 2014 10/ 2014] Available from: http://theicct.org/sites/default/files/ publications/ICCT_state-EV-incentives_20141030.pdf

36. Advanced Research Projects Agency-Energy (ARPA-E). Projects. 2015. [cited 2015 5/23/2015] Available from: http://arpa-e.energy. gov/?q=arpa-e-site-page/view-programs.

37. Joint Center for Energy Storage Research (JCESR). Home. 2015. [cited 2015 5/23/2015] Available at: http://www.jcesr.org/.

38. Department of Energy (DOE). Programs. 2015a. [cited 2015 5/23/ 2015] Available from: http://energy.gov/lpo/projects.

39. Sims REH, Hans-Holger R, Gregory K. Carbon emissions and mitigation cost comparisons between fossil fuel, nuclear, and renewable energy resources for electricity generation. Energy Policy. 2003;31:1315-26.

40. Nykvist B, Nilsson M. Rapidly falling costs of battery packs for electric vehicles. Nat Clim Chang. 2015;5:329-32. 
41. Tal G, Nicholas MA, Davies J, Woodjack J. Charging behavior impacts on electric vehicle miles traveled: who is not plugging in? Transportation Research Record. 2014; 53-60.

42. Department of Energy (DOE). EV everywhere workplace charging challenge. 2015b. [cited 2015 5/23/2015] Available at: http://energy.gov/eere/vehicles/ev-everywhere-workplacecharging-challenge.

43. Washington Department of Transportation (WDOT). West Coast Electric Highway. 2015. [cited 2015 5/23/2015] Available at: http://www.westcoastgreenhighway.com/electrichighway.htm. 